\title{
Multi-hazard assessment in Europe under climate change
}

\author{
Giovanni Forzieri $^{1} \cdot$ Luc Feyen $^{1} \cdot$ Simone Russo $^{2}$ • \\ Michalis Vousdoukas ${ }^{1,3} \cdot$ Lorenzo Alfieri $^{1}$. \\ Stephen Outten $^{4} \cdot$ Mirco Migliavacca $^{5}$.

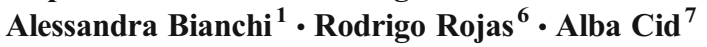

Received: 7 July 2015 /Accepted: 25 March 2016/Published online: 19 April 2016

(C) The Author(s) 2016. This article is published with open access at Springerlink.com

\begin{abstract}
While reported losses of climate-related hazards are at historically high levels, climate change is likely to enhance the risk posed by extreme weather events. Several regions are likely to be exposed to multiple climate hazards, yet their modeling in a joint scheme is still at the early stages. A multi-hazard framework to map exposure to multiple climate extremes in Europe along the twenty-first century is hereby presented. Using an ensemble of climate projections, changes in the frequency of heat and cold waves, river and coastal flooding, streamflow droughts, wildfires and windstorms are evaluated. Corresponding variations in expected annual exposure allow for a quantitative comparison of hazards described by different process characteristics and metrics. Projected changes in exposure depict important variations in hazard scenarios, especially those linked to rising temperatures, and spatial patterns largely modulated by local climate conditions. Results show that Europe will likely
\end{abstract}

Electronic supplementary material The online version of this article (doi:10.1007/s10584-016-1661-x) contains supplementary material, which is available to authorized users.

Giovanni Forzieri

giovanni.forzieri@jrc.ec.europa.eu

1 European Commission, Joint Research Centre (JRC), Institute for Environment and Sustainability (IES), Climate Risk Management Unit, Via Enrico Fermi 2749, 21027 Ispra, VA, Italy

2 European Commission, Joint Research Centre (JRC), Institute for Environment and Sustainability (IES), Econometrics and Applied Statistics Unit, Via Enrico Fermi 2749, 21027 Ispra, VA, Italy

3 Department of Marine Sciences, University of the Aegean, University hill, 41100 Mitilene, Lesbos, Greece

4 Nansen Environmental and Remote Sensing Center, Thormhlensgt, 47, 5006 Bergen, Norway

5 Biogeochemical Integration Department, Max Planck Institute for Biogeochemistry, 07745 Jena, Germany

6 CSIRO, Land and Water, Private Bag Nr 5, PO Wembley, Perth, WA 6913, Australia

7 Environmental Hydraulics Institute, IH Cantabria, Universidad de Cantabria, C/ Isabel Torres 15, PCTCAN, 39011 Santander, Spain 
face a progressive increase in overall climate hazard with a prominent spatial gradient towards south-western regions mainly driven by the rise of heat waves, droughts and wildfires. Key hotspots emerge particularly along coastlines and in floodplains, often highly populated and economically pivotal, where floods and windstorms could be critical in combination with other climate hazards. Projected increases in exposure will be larger for very extreme events due to their pronounced changes in frequency. Results of this appraisal provide useful input for forthcoming European disaster risk and adaptation policy.

\section{Introduction}

Europe is expected to face major impacts from a changing climate over the coming decades (Kreibich et al. 2014). The hazard to society and environment will be largely connected to changes in extreme climate events due to their disproportionate rise compared to the corresponding change in climatological averages (Rummukainen 2012). Threats will be more pronounced in areas prone to multiple climate hazards. In this context, a multi-hazard assessment accounting for possible regional variations in intensity and frequency of climate extremes is essential to identify areas potentially more exposed to climate change.

A number of climate change impact studies at the European level have been achieved, usually for a single specific climate or weather hazard, such as river floods (Rojas et al. 2012; Alfieri et al. 2015), coastal floods (Nicholls and Klein 2005; Hinkel et al. 2010), heat waves (Fischer and Schär 2010; Russo et al. 2015; Christidis et al. 2015), streamflow droughts (Lehner et al. 2006; Forzieri et al. 2014), windstorms (Nikulin et al. 2011; Outten and Esau 2013) and wildfires (Bedia et al. 2013; Migliavacca et al. 2013a). The study of multiple hazards poses two major challenges: (1) hazards are not directly comparable as their processes and describing metrics differ; and (2) hazards can interact triggering cascade effects and coupled dynamics. In the existing literature, the first issue has been mainly addressed through standardization approaches, such as classification of hazard intensity and development of continuous indices (Dilley 2005; Kappes et al. 2012; Lung et al. 2013). While these approaches represent a starting point, they describe only a limited set of climate hazards and the techniques used to make different hazards comparable are largely subjective and inconsistent. The second issue has been addressed mainly qualitatively through descriptive matrices where coupled mechanisms are conceptualized based on multi-hazard dynamics observed at local scale and largely influenced by landscape figures (Kappes et al. 2012; Gill and Malamud 2014). Deeper data-driven investigations are needed before interactions between hazards can be reliably incorporated into large-scale predictive systems. Thus, in this study we mainly focus on the first above-mentioned challenge.

Through a unique collaborative effort of different European modeling groups, a consistent set of climate hazard modeling data has been produced for this study including heat and cold waves, river and coastal floods, droughts, wildfires and windstorms. Future climate hazards in Europe have been generated for an ensemble of regional climate simulations under a "business-as-usual" (SRES A1B) greenhouse gas (GHG) emissions trajectory (Solomon 2007) and synthesized in a coherent multi-hazard framework. The method is based on the analysis of the changes in frequency of climate-induced extreme events and the corresponding variations in expected annual exposure to these events. The latter is hereafter defined as Expected Annual Fraction Exposed (EAFE), where the fraction can relate to any variable of interest (e.g., population, cropland). For a range of hazard severities, single-hazard EAFEs and changes therein are combined into multihazard indices to synthesize the potential exposure to multiple climate hazards (Methods). This 
work provides the first comprehensive multi-hazard assessment for Europe under climate change and focuses in particular on the comparability amongst single-hazard exposures and on the degree of overlap between areas exposed to multiple hazards throughout this century. The overall goal is to identify geographic areas with the highest potential exposure to multiple climate hazards in order to better steer adaptation efforts and land planning across Europe. It is worth to stress that this contribution should not be confused with a risk assessment study. Risk assessments imply the combination of hazard, vulnerability and spatial distribution of settlements (e.g., population, assets). In this work we focus on the hazard component, the integration of local vulnerabilities of settlements to different types of hazards will be tackled in a separated research work. Results are shown in spatial maps as well as aggregated for five European regions to simplify interpretation (Figure S1, Supplementary Material): Southern, Western, Central, Eastern and Northern Europe.

\section{Methods}

\subsection{Climate hazard indicators}

The analysis focuses on seven critical climate hazards for Europe: heat and cold waves, river and coastal floods, droughts, wildfires and windstorms, each one described by an indicator that relates to the physical impact (magnitude of warm/cold period, flood extents, minimum discharge, burned area, wind speed, Text S1 Supplementary Material). Climate hazard indicators were derived for the baseline (1981-2010), 2020s (2011-2040), 2050s (2041-2070) and 2080s (2071-2100) for an ensemble of climate projections obtained from different Global Circulation Model-Regional Climate Model (GCM-RCM) simulations under the A1B emissions scenario (Solomon 2007) (table S1, Supplementary Material). Precipitation and temperature fields utilized in our study as climatic drivers have been bias corrected by the quantile method (Dosio and Paruolo 2011).

Heatwaves were defined by the Heat Wave Magnitude Index daily (HWMId) that is based on the daily maximum temperature anomalies (Russo et al. 2015). Cold waves were similarly calculated by referring to minimum temperatures. Return levels of heat and cold waves were retrieved by kernel density estimator with triangular kernel. Wildfires were derived from projections of the monthly percentage of burned area (Migliavacca et al. 2013a). Beta functions were selected to fit the annual fractions of burned area and to derive extreme events. Extreme windstorms were calculated using the Generalized Pareto distributions that have been derived through a peak-over-threshold analysis for daily maximum wind speeds (Outten and Esau 2013). Relative Sea Level Rise projections were combined with current extreme value distributions of total water levels obtained using a peak-over-threshold method (Pardaens et al. 2011; Cid et al. 2014). Following, a static inundation approach was applied to generate inundation maps along the coastline. For inland flooding the annual maximum discharges and flood inundation maps were derived from earlier works (Rojas et al. 2012; Rojas et al. 2013). For drought the minimum discharges and return levels were obtained from a previous study (Forzieri et al. 2014). Details in Text S1, Supplementary Material. All climate hazard indicators have been scaled to the common 1000-m grid. Figure S2 shows the spatial modeling domain for each hazard. Note that for river and coastal floods the baseline 500-yr. flood extension is used as reference modelling domain. Details in Text S2, Supplementary Material. 


\subsection{Frequency of extreme events in current and future climate}

Baseline return levels $\left(R_{L, b}\right)$ of the climate hazard indicators with return periods $\left(T_{R, b}\right)$ from 2 to 100 years were obtained at each grid cell. Future return periods $\left(T_{R, f}\right)$ of $R_{L, b}$ were calculated by inversion of the fitted probability functions $(G)$.

$$
T_{R, f}\left(R_{L, b}\right)=\frac{1}{1-G\left(R_{L, b}\right)}
$$

Climate model variability was quantified by the coefficient of variance of the future return periods retrieved for the different climate realizations. The significance of the changes in climate hazard was evaluated by the Kolmogorov-Smirnov test applied on the annual values of future time windows versus baseline, separately for each climate model.

\subsection{Expected annual fraction exposed}

By analogy with risks of extreme events that are often communicated in terms of expected annual impact, the fraction expected to be annually exposed to a hazard - the Expected Annual Fraction Exposed (EAFE) - was calculated by integrating the exposure to hazard events over the probability of occurrence distribution of the hazard. The share of exposure from hazard events with return period $\geq T_{R}$ was obtained as in the following:

$$
\operatorname{EAFE}\left(T_{R}\right)=\int_{0}^{\frac{1}{T_{R}\left(R_{L}\right)}} f \mathrm{dp}
$$

where $f$ is the exposure-probability function. In the case of river and coastal floods $f$ is a dummy function with value 1 when the pixel is flooded, 0 otherwise. For the remaining climate hazard indicators $f$ is a constant function equal to 1 , under the assumption that exposure to the hazard is spread homogeneously within the pixel. Future return periods retrieved from equation [1] are used to truncate the integration for future EAFE. For pixels with non-significant changes we keep baseline values for future EAFE. EAFE ranges between 0 (no exposure to the hazard) and 1 (whole fraction expected to be annually exposed to climate hazard). The use of EAFE allows comparing quantitatively multiple hazards characterized by different processes and time scales based on a common intensity scale derived from the probability of occurrence of extreme events in the current climatology. For each hazard, EAFE has been computed at pixel level for the corresponding set of GCM-RCM configurations, resulting in a grid-cell ensemble of hazard-specific EAFE values that reflects the variability in climate projections.

\subsection{Combining multiple hazards}

To quantify the total expected annual exposure to multiple hazards we define the Overall Exposure Index (OEI). Under the assumption that the considered hazards are 
mutually non-exclusive, from the inclusion-exclusion principle of combinatorics the OEI can be expressed as follows for a given $T_{R}$ :

$$
\operatorname{OEI}\left(T_{R}\right)=\bigcup_{i=1}^{n} \operatorname{EAFE}_{i}\left(T_{R}\right)=\sum_{k=1}^{n}\left((-1)^{k-1} \sum_{\substack{I \subset\{1, \ldots, n\} \\|I|=k}} \operatorname{EAFE}_{I}\left(T_{R}\right)\right),
$$

where $i$ refers to the hazard-specific EAFE, $n$ is the number of hazards considered, the last sum runs over all subsets $I$ of the indices $\{1, \ldots, n\}$ containing exactly $k$ elements, and

$$
\operatorname{EAFE}_{I}\left(T_{R}\right):=\bigcap_{i \in I} \operatorname{EAFE}_{i}\left(T_{R}\right)
$$

expresses the intersection of all those $\mathrm{EAFE}_{\mathrm{i}}$ with index in $I$. Equation [3] quantifies the exposure to at least one climate hazard. To account for the overall exposure to $m$ overlapping hazards, equation [3] can be generalized using the intersections of $m$ EAFEs in place of single-hazard components (details in Text S3 and Fig. S3, Supplementary Material). Here, we use $m$ values up to three to quantify different degree of overlap amongst hazards.

To identify areas subject to large increases in exposure to multiple hazards, we define the Change Exposure Index (CEI). CEI expresses the number of hazards - of a given baseline return level - with a future relative increase in EAFE over a certain threshold $(20 \%, 100 \%$ and $1000 \%$ ). The use of three different thresholds allows capturing moderate, strong and extreme changes in hazard exposure. The number of hazards with an increase in exposure over the given threshold is calculated in each grid cell and then aggregated at NUTS3 level as the 0.99 percentile of this distribution over all cells. The 99th percentile of the exposure change distribution within the NUTS3 region excludes local fitting extrapolation errors and is considered representative of the maximum degree of change in exposure. CEI allows identifying key hotspots subject to predefined levels of change in exposure (details in Text S4, Supplementary Material).

For the spatial domain common to all hazards OEI and CEI are calculated for each return level and time slice using the ensemble median of all climate model combinations for each hazard as inputs because only one single GCM-RCM configuration is common amongst the hazards (Table S1). To understand the possible effects of climate uncertainty on multi-hazard metrics, OEI and CEI have been also calculated for the maximum and minimum hazard scenarios obtained by combining the single-hazard grid-cell ensemble maximum and minimum, respectively, as inputs.

\section{Results and discussion}

\subsection{Single-hazard impacts}

Figure 1 shows the projected changes in frequency of climatic extreme events with respect to current climate, where increasing (decreasing) hazard occurrences are denoted by lines under (over) the bisector, the coefficient of variance (CV) describes the inter-model spread (climate 
uncertainty) and $\mathrm{S}$ values the percentage of area subject to significant changes ( $5 \%$ level). The frequency analysis is complemented with the corresponding variations in Expected Annual Fraction Exposed (EAFE) shown in Fig. 2 both in terms of its magnitude and relative change with respect to the baseline; whiskers refer to the range of variability connected to the minimum/maximum hazard scenarios. Corresponding spatial patterns of EAFE are shown in Figure S4. Heat waves show a progressive and highly significant increase in frequency all over Europe ( $\mathrm{S}>73 \%$ in near future climate, approaching $100 \%$ in all regions by the end of this century), with larger climate variability in long-term scenarios $(40 \leq \mathrm{CV} \leq 60)$ and a more pronounced intensification in Southern Europe (where current 100-yr. events could occur almost every year in the 2080s) (Fig. 1). Consistently, EAFE values show a progressive increase as time proceeds, especially in Southern Europe where, by the end of the century, up to $60 \%$ of the territory could be annually exposed to a current 100-year heat wave (Fig. 2). Cold waves show an opposite trend with current cold extremes tending to mostly disappear in Europe in more distant futures (current 2-yr. event may occur less than every 100 years by the end of the century, significant almost everywhere, Fig. 1). Accordingly, cold waves could experience a rapid decrease in EAFE and a change up to $-100 \%$ by the end of the century (Fig. 2). Streamflow droughts may become more severe and persistent in Southern and Western Europe (current 100-yr. events could occur approximately every 2 to 5 years by 2080 , respectively, $S \geq 85$ ) resulting from the reduced precipitation and increased evaporative demands with higher temperatures (Fig. 1). This leads to a consistent increase in EAFE and by the end of the century over $25 \%$ of the territories could be affected every year by baseline 100 yr. droughts (Fig. 2). Northern, Eastern and Central Europe show an opposite tendency with a strong reduction in drought frequency (Fig. 1) caused by higher precipitation that outweigh the effects of increased evapotranspiration (Forzieri et al. 2014). Such effects translate mostly into consistent decreases in EAFE up to $-100 \%$ (Fig. 2). Significance increases with time while climate variability shows variable tendencies depending on the return levels ( $\mathrm{S}>75 \%$ and $\mathrm{CV}$ over $60 \%$ by the end of the century). Most of Europe, especially Western, Eastern and Central regions, could experience an increase in the frequency of extreme wildfires (current 100-yr. events will occur every 5 to 50 years) with a progressive rise in significance and model agreement ( $\mathrm{S}>10 \%$ and $\mathrm{CV} \leq 60 \%$ by the end of the century) (Fig. 1). Interestingly, Southern Europe shows a decrease in the frequency of very extreme events, which is likely due to the expected reduction in net primary productivity of terrestrial ecosystem that may limit the fuel availability and, ultimately, the propagation of large wildfires (Migliavacca et al. 2013a). Progressive increases in EAFE are visible for wildfires over the whole domain (one to threefolds the baseline value, Fig. 2). River floods show in general more spatial variability and fluctuations with time in the frequency of extreme events as well as a larger climate-induced spread compared to the other hazards (higher CV values, Fig. 1). This relates to the high variability in projected geographical patterns of heavy precipitation intensity due to structural and parametric model uncertainty and internal climate variability (Fischer et al. 2013). Western Europe shows a consistent rise in future flood hazard (current 100-yr. events could manifest every $\sim 30$ years in 2080 s, S up to $70 \%$ ), mainly as a result of a pronounced increase in average and extreme rainfall (Rojas et al. 2012). Such effects result in a 50-100 \% increase in future EAFE (Fig. 2). A modest but significant decrease in river flood frequency is projected in Southern, Central and Eastern regions, in the latter because of the strong reduction in snowmelt induced river floods, which offsets the increase in average and extreme precipitation. Coastal floods show a progressive and pronounced increase in recurrence along Europe's coastlines chiefly caused by sea level rise (current 100-yr. event may manifest every 2 to 8 years, or even 
sub-annually in Eastern Europe, in the 2080s, Fig. 1) and leading to strong increase in EAFE (Fig. 2). Noteworthy is the pronounced increase in EAFE in Eastern Europe as a consequence of the rapid intensification of inundations over the Danube delta. Evidence for changes in windstorms remains largely elusive $(\mathrm{S}<16 \%)$ and with considerable inter-model spread for larger return levels (up to CV $>60 \%$ for current 100-yr. events, Fig. 1). Areas with increases in windstorm hazard are mainly located in Western, Eastern and Northern Europe, while Southern regions present slight reductions in frequency as observed in previous studies (Nikulin et al. 2011; Outten and Esau 2013). EAFE of windstorms show modest changes with respect to the baseline (up to $\pm 10 \%$, Fig. 2).

Interestingly, larger increases in EAFE can be observed at higher return levels and for longterm scenarios due to the progressive intensification of very extreme events. This occurs also in regions prevalently experiencing a reduction (or slight change) in future frequency of climate hazards, such as Central and Eastern Europe for droughts, Southern Europe for wildfires and Southern, Central and Northern Europe for floods. The apparent contradiction manifests where few localized areas experience a very large increase in frequency that outweighs the opposite tendency occurring in most of the region.

Projected changes in single-hazard exposure suggest that future hazard scenarios will considerably deviate from those observed in current climate, especially for climate hazards strongly linked to temperature rises (e.g., heat and cold waves, droughts and coastal floods). Despite the general good agreement in the direction of change in exposure amongst the minimum/maximum hazard scenarios (whiskers in Fig. 2) opposite variations in EAFE are apparent in some situations. This is evident for droughts in Central, Eastern and Northern Europe where upper and lower bounds of the range are greater and lower, respectively, than the baseline value (e.g., 0.01 for 100-yr. baseline return period). A deeper inspection of the EAFEs values originated from single GCM-RCM combinations reveals that changes of different hazards may present a dependence across models, with generally more pronounced increases in exposure in models with a larger overall warming (e.g., C4I-RCA-HadCM3, METOHadRM3-HadCM3, Fig. S5).

\subsection{Changes in overall and concurrent exposures}

Figure 3a shows the overall exposure of each European region resulting from the combination of all hazards, expressed by the Overall Exposure Index accounting for the different number of overlapping hazards (OEI); whiskers express the combination of model uncertainty and internal variability connected to the minimum/maximum multi-hazard scenarios. The positive gradient in $\triangle \mathrm{EAFE}$ for increasing return levels is more pronounced than in single-hazard scenarios. This results mainly from the combined effect of the abrupt reduction of cold waves and droughts - the latter only for North-eastern and Central Europe - and the compensation occurring at high return levels when the marked positive changes of remaining hazards outweigh such effects (EAFE(100-yr) up to 0.77 by the end of the century for $\mathrm{OEI}_{1}$, about ten-fold the baseline value). The 100-yr. return level remains the most relevant in terms of projected increase of expected annual exposure, especially when overlapping of multiple hazards is accounted for (EAFE(100-yr) up to 0.25 and 0.006 for $\mathrm{OEI}_{2}$ and $\mathrm{OEI}_{3}$, respectively, about thirty-fold the baseline value). Looking at the combination of 100-yr. extreme events, results suggest that the entire Europe could face a progressive increase in overall climate exposure, with a prominent spatial gradient towards south-western regions (Fig. 3b). Heat waves, droughts and wildfires, which are particularly effective in such regions, likely provide 


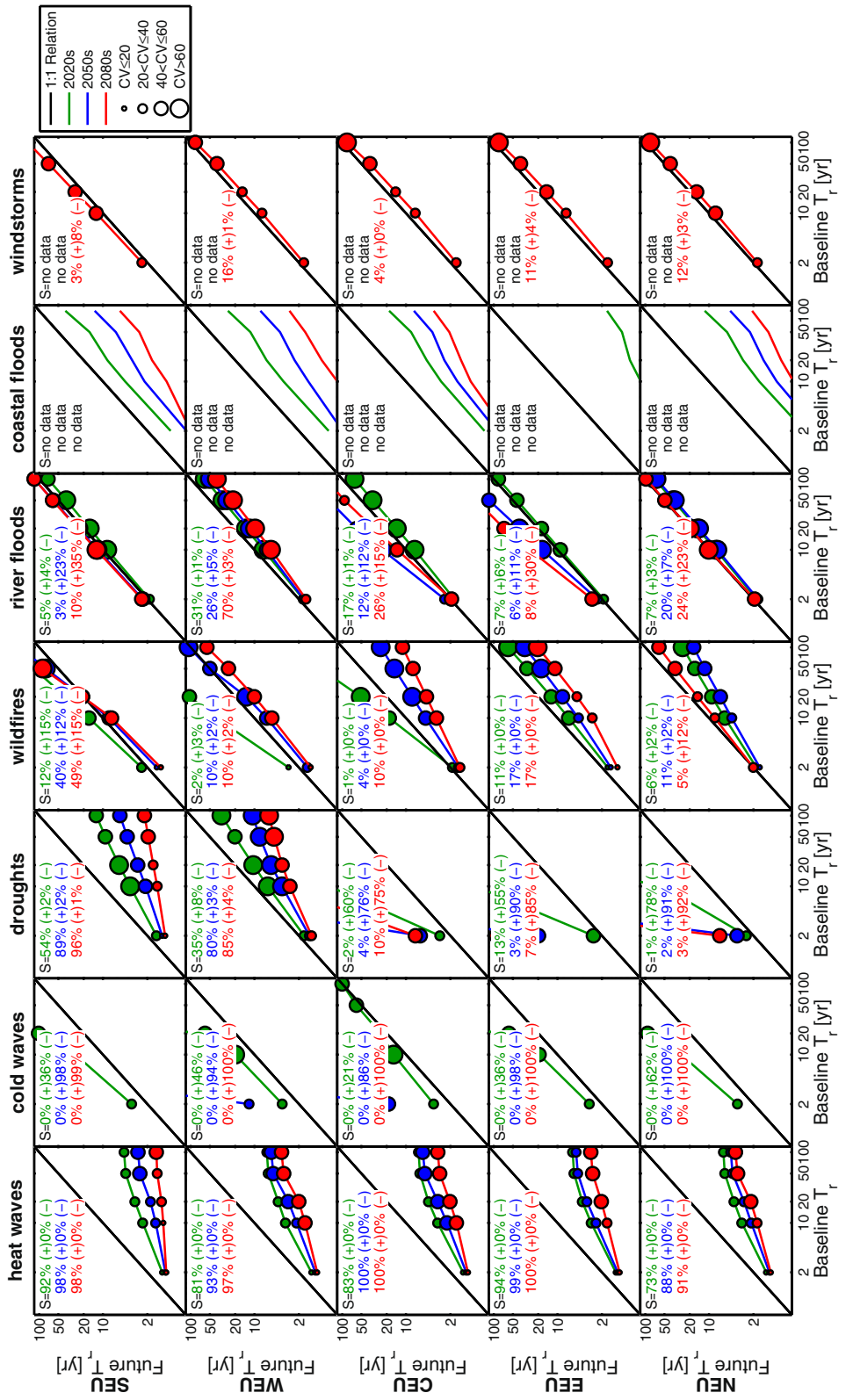

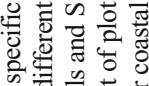

tᄒ

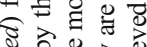

은 원.

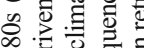

ते

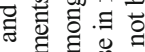

₹. है

इ 늉

电证:

ते

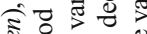

है,

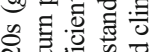

楁卷

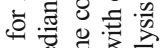

च छ

웡

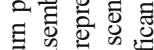

를 कू

च च ह

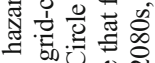

(2)

的范

00 迁节

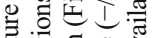

要总震

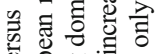

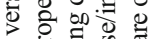

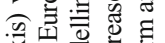

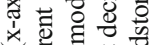

氙节

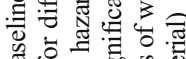

氙

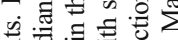

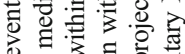

즘 $\frac{3}{0}$.

윤.

응 호을

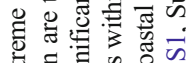

进的

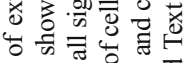

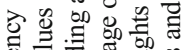

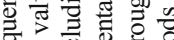

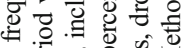

$\exists$ के के

ง

品焉:

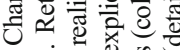

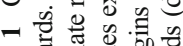

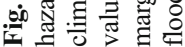




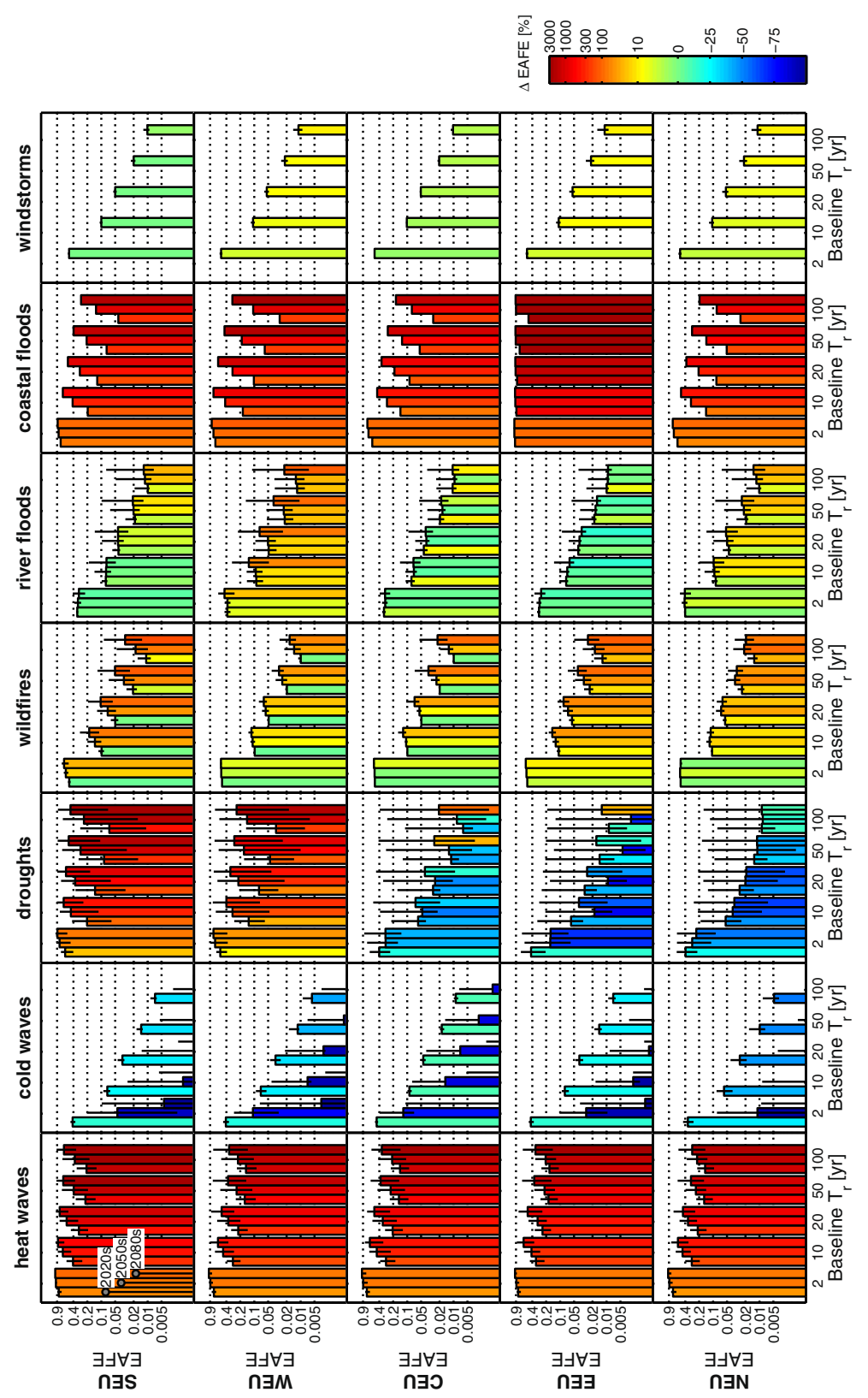

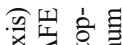

离近贯

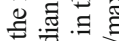

흘

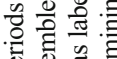

당

항

可

군

हn

匹

息宛

设表汽

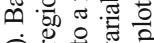

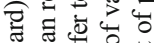

ฮ 응

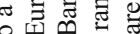

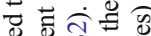

융 क 의

중 =

눙.

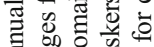

的

\& $:$

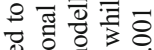

잉

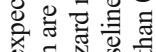

ช 도웛

궁웡

n $\neq$ 으

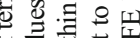

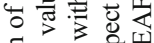

돈

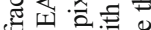

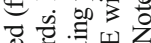

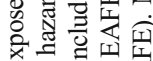

空可品

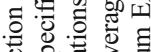

放密

車

要离边

穴流

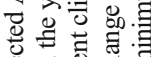

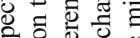

乐

준

너

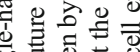

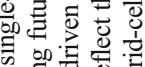

䏝

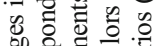

의응

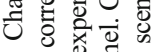

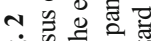

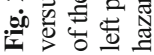


the most relevant contribution in the estimation of future OEI (Fig. S4, Supplementary Material).

Figure $4 \mathrm{a}$ shows for each European region the spatial extent experiencing pronounced changes in at least four hazards as expressed by the Change Exposure Index calculated for different levels of increase in exposure (CEI), whiskers refer to the climate variability connected to the minimum/maximum multi-hazard scenarios. Areas with potential concurrent exposures tend to increase with the return level and for the long-term scenarios, consistently to the pronounced variations in very extreme events. The spatial pattern of CEI (Fig. 4b) reveals potential key hotspots that are potentially prone to an increase in exposure to multiple hazards. These are mainly located along coastlines and in floodplains where windstorms and floods will be likely relevant in combination with temperature-related hazards (hazard-specific contributions shown in Fig. S6, Supplementary Material). More exposed regions include the British Isles, the North Sea area, north-western parts of the Iberian Peninsula, as well as parts of France, the Alps, Northern Italy and Balkan countries along the Danube River. These areas, even if they may present lower overall climate exposure compared to other regions in Europe (Fig. 3b), will be prone to the largest changes in multi-hazard exposures that could potentially results in larger risks.

Relevant climate variability emerges for both OEI and CEI, more pronounced for long-term scenarios, larger return periods and higher degree of overlapping/change when compared to their median values (Fig. 3a and 4a), largely consistent to the ranges of variability observed in minimum/maximum single-hazard EAFE scenarios (Fig. 2). We argue that the uncertainty captured by the minimum and maximum scenarios tends to overestimate the one that would originate ideally from a combination of each model individually into multi-hazard metrics. Then, sampled ranges of variability should be considered as a qualitative proxy of how model uncertainties of single hazards propagate into multi-hazard metrics.

\subsection{Sources of uncertainty}

Despite the depth of this study, results should be viewed in light of the potential uncertainty sources and caveats of the proposed methodology. The multi-hazard maps are dependent on the chosen set of climate hazard indicators: the use of diverse input hazards (e.g., hail, landslides) might lead to different findings. We argue that the set of hazards selected includes the most relevant hazards for Europe in terms of average annual losses and deaths (Guha-Sapir et al. 2014; NatCatSERVICE 2015). Metrics used to represent the selected climate hazards are crucial for the resulting impact scenarios: changes in return periods depend on the time scale selected to characterize an event type, e.g. 1-day temperature extremes, weekly heatwaves or seasonal heat anomalies experience different changes in return periods (Perkins and Alexander 2012; Trenberth et al. 2014). In our approach we focus on hazard-specific metrics of impact relevance that have been documented in recent literature. Details on the sensitivity analysis and calibration/validation exercises for each single hazard are reported in the references (Rojas et al. 2012; Migliavacca et al. 2013b; Outten and Esau 2013; Forzieri et al. 2014; Cid et al. 2014; Russo et al. 2014). We recognize that extreme value fitting and kernel density estimators may introduce additional uncertainty in the projections of climate hazards especially at high return periods. Recent studies, though, documented its secondary role with respect to the inter-model spread (Rojas et al. 2012; Forzieri et al. 2014).

We apply a conservative approach without accounting explicitly for hazard interrelations that could lead to greater impacts. Regions exposed to the overlap of multiple hazards and 


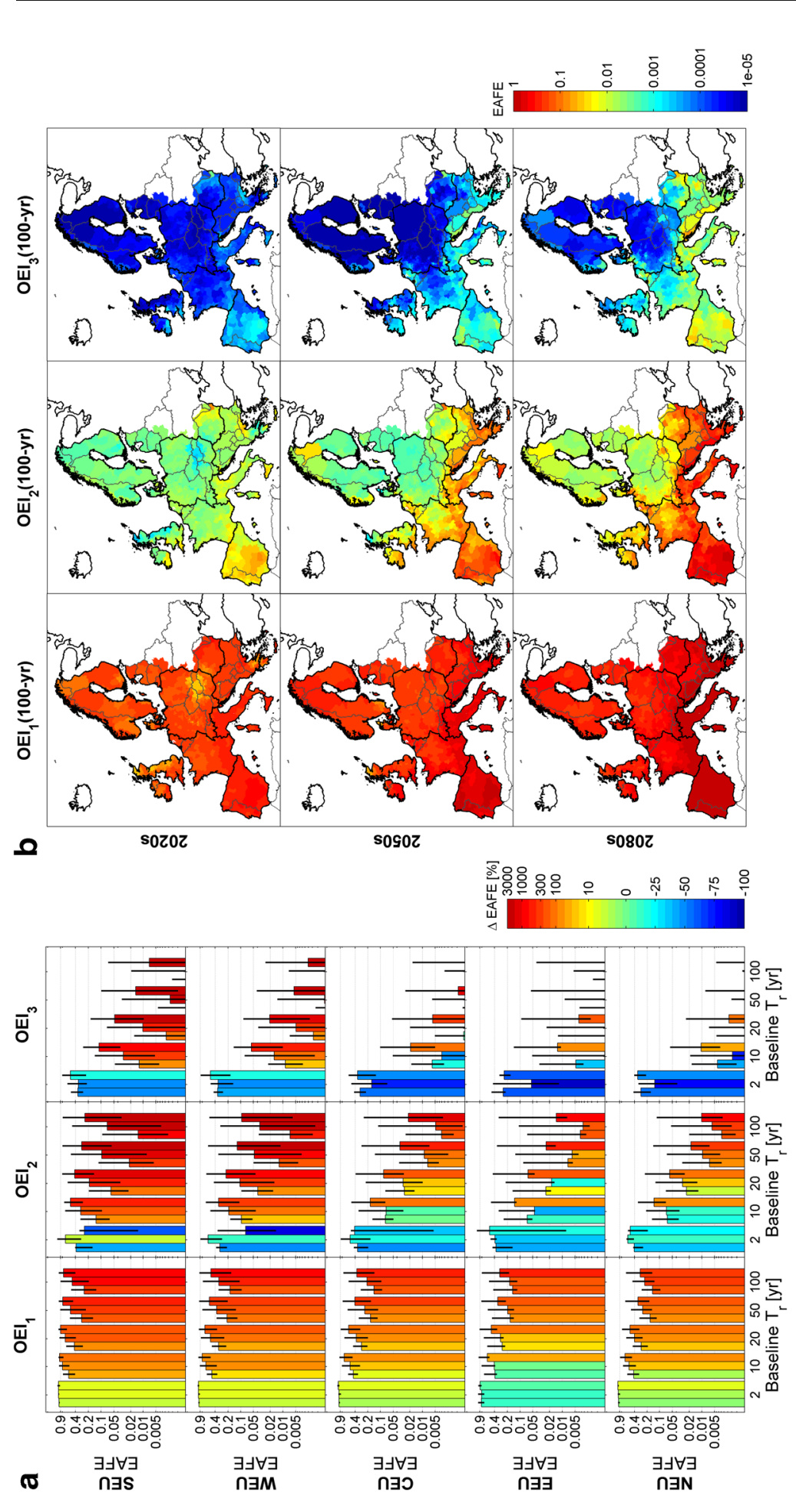

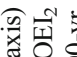

용

엉 峲

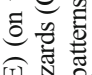

空 흔

凷

च

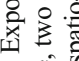

है क

के

tis

蛋

¿ ठ

월

훙

战

导要

on

흥 홍

क्ष

ठ․ㄹ

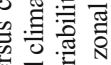

ज政

की

\%

$\star$. त्ज़

울

흥 क्षँ

의

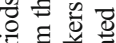

区․ㅠ. 目范 春讨 矛的 w 羟 ๙ 局 0 을. o is 苛总 웡 8 乐宇氞 픈 ठำ

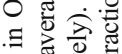

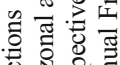

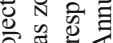
列 m $\frac{\mathrm{s}}{3}$ 讪 받 $\frac{0}{\pi}$ 完 


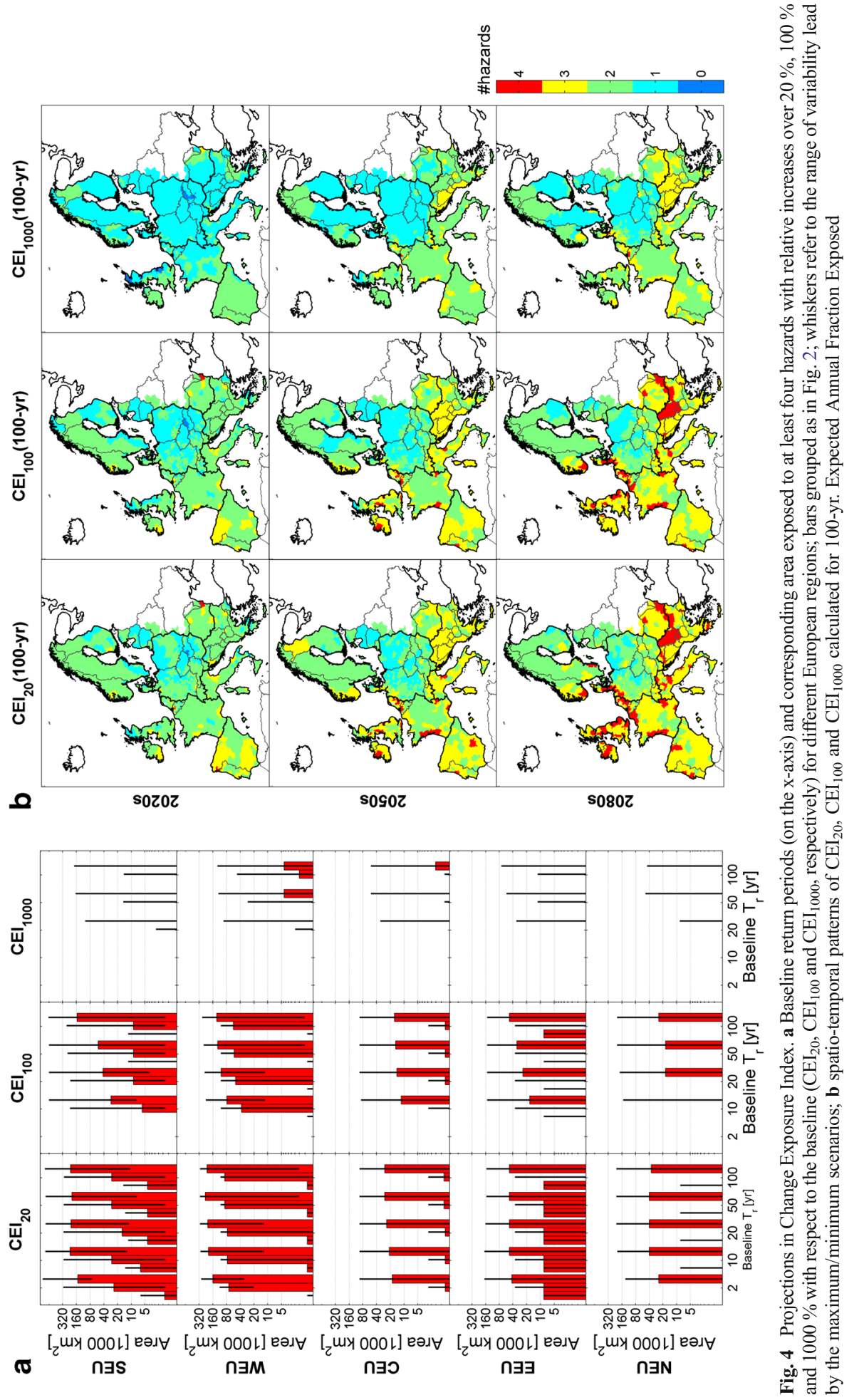


subject to concurrent increases in single-hazard EAFEs, however, are indicative of a more likely exacerbation of the overall impacts due to inter-hazard triggering relationships. Estimation of probabilities of coincidental or cascading events would require finer time resolution of hazard metrics (here annual or monthly) and a better knowledge of the interhazard physical interactions and coupled processes.

The socioeconomic scenarios driving GHG emissions, the sensitivity of the climate models to GHG concentrations and the specific hazard modelling utilized are subject to uncertainty, and all are relevant in influencing the final multi-hazard assessment. The use of different climate model ensembles for each hazard may have introduced additional artifacts (Table S1, Supplementary Material). However, recent studies suggest that the reduced subsets utilized in this study for some hazards largely preserve main statistical properties of the initial 12-member ensemble (Russo et al. 2013). The use of identical - and possibly larger - ensembles could allow to better capturing climate-related uncertainties (Kharin et al. 2013; Sillmann et al. 2013). We used a different baseline and only one future time window for windstorms (see text S1, Supplementary Material). New dedicated runs for windstorms for the remaining temporal periods were not feasible within this study. We understand that such diversity may limit the comparability with the other hazards; however, changes in extreme winds seem to be lower compared to the other climate hazards, hence the potential bias is expected to play a minor role. Analyses of the multi-hazard indices are performed using the ensemble median (and minimum/maximum) of all climate model combinations for each hazard as input because only one single GCM-RCM configuration is common amongst the hazards. While the median can be considered a robust estimate of single-hazard ensembles, this inevitably hampers the analysis of how single-hazard uncertainties (Fig. 1) propagate to the combined metrics, especially in light of possible dependences of hazards across climate models (Figure S5).

\subsection{Conclusions}

The multi-hazard assessment presented here contributes to understanding to what extent climate-related extreme events will take place under climate change. In particular, the use of a common reference unit based on the probability of occurrence of extremes in current climatology allows comparing the changes in hazard frequency amongst multiple climate extremes and to quantitatively compare them. The adopted homogenized intensity scale permits identifying those hazards that will likely manifest larger changes in exposed areas along the twenty-first century. The combination of changes in multiple climate extremes into single indices leads to a clearer detection of changes in total hazard exposure thanks to the enhanced signal-to-noise ratio. The joint scheme proposed to quantify the overall multi-hazard exposure and concurrent increases in exposure enables the identification of areas in Europe that are likely to be most endangered by multiple climate hazards along the twenty-first century. Key findings can be summarized as in the following:

- Projected changes in the occurrence of the seven climate extremes depict important variations in hazard scenarios with large spatial patterns modulated by local climate conditions.

- Europe will see a progressive and strong increase in overall climate hazard with a prominent spatial gradient towards south-western regions.

- Key hotspots emerge particularly along coastlines and in floodplains in Southern and Western Europe, which are often highly populated and economically pivotal. 
Results - interpreted in light of exposed assets and their vulnerability - provide useful input to derive future multi-hazard risk scenarios and support adaptation strategies to increasing Europe's resilience to climate change.

Acknowledgments G.F. and L.F. conceived and designed the study, G.F. and S.O. analyzed windstorms, G.F. analyzed streamflow droughts, G.F. and M.M. analyzed wildfires, S.R. analyzed heat and cold waves, M.V. and A.C. analyzed coastal floods, R.R. and L.A. analyzed river floods, G.F. and A.B. harmonized the climate hazards, G.F. developed the multi-hazard indices. G.F. and L.F. wrote the paper with contributions from all the authors. This research was supported by the CCMFF Project, funded by the DG Climate Action (ref. 071303/2012/ 630715/CLIMA.C.3) and the FP7 ENHANCE project (grant agreement number 308438) funded by the European Commission.

Open Access This article is distributed under the terms of the Creative Commons Attribution 4.0 International License (http://creativecommons.org/licenses/by/4.0/), which permits unrestricted use, distribution, and reproduction in any medium, provided you give appropriate credit to the original author(s) and the source, provide a link to the Creative Commons license, and indicate if changes were made.

\section{References}

Alfieri L, Burek P, Feyen L, Forzieri G (2015) Global warming increases the frequency of river floods in Europe. Hydrol Earth Syst Sci 19:2247-2260. doi:10.5194/hess-19-2247-2015

Bedia J, Herrera S, Camia A, et al. (2013) Forest fire danger projections in the Mediterranean using ENSEMBLES regional climate change scenarios. Clim Chang 122:185-199. doi:10.1007/s10584-013-1005-Z

Christidis N, Jones GS, Stott PA (2015) Dramatically increasing chance of extremely hot summers since the 2003 European heatwave. Nat Clim Chang 5:46-50. doi:10.1038/nclimate2468

Cid A, Castanedo S, Abascal AJ, et al. (2014) A high resolution hindcast of the meteorological sea level component for Southern Europe: the GOS dataset. Clim Dyn 43:2167-2184. doi:10.1007/s00382-013-20410

Dilley M (2005) Natural disaster hotspots: A Global risk analysis. World Bank Publications

Dosio A, Paruolo P (2011) Bias correction of the ENSEMBLES high-resolution climate change projections for use by impact models: Evaluation on the present climate. J Geophys Res Atmospheres 116:D16106. doi:10. 1029/2011JD015934

Fischer EM, Schär C (2010) Consistent geographical patterns of changes in high-impact European heatwaves. Nat Geosci 3:398-403. doi:10.1038/ngeo866

Fischer EM, Beyerle U, Knutti R (2013) Robust spatially aggregated projections of climate extremes. Nat Clim Chang 3:1033-1038. doi:10.1038/nclimate2051

Forzieri G, Feyen L, Rojas R, et al. (2014) Ensemble projections of future streamflow droughts in Europe. Hydrol Earth Syst Sci 18:85-108. doi:10.5194/hess-18-85-2014

Gill JC, Malamud BD (2014) Reviewing and visualizing the interactions of natural hazards. Rev Geophys 52: 2013RG000445. doi:10.1002/2013RG000445

Guha-Sapir, D, Hoyois, Ph, Below, R (2014) Annual disaster statistical review 2013, the numbers and trends. Centre for Research on the Epidemiology of Disasters (CRED), Brussels, Belgium

Hinkel J, Nicholls RJ, Vafeidis AT, et al. (2010) Assessing risk of and adaptation to sea-level rise in the European Union: an application of DIVA. Mitig Adapt Strateg Glob Change 15:703-719. doi:10.1007/s11027-0109237-y

NatCatSERVICE | Munich Re. http://www.munichre.com/natcatservice. Accessed 26 May 2015

Kappes MS, Keiler M, von Elverfeldt K, Glade T (2012) Challenges of analyzing multi-hazard risk: a review. Nat Hazards 64:1925-1958. doi:10.1007/s11069-012-0294-2

Kharin VV, Zwiers FW, Zhang X, Wehner M (2013) Changes in temperature and precipitation extremes in the CMIP5 ensemble. Clim Chang 119:345-357. doi:10.1007/s10584-013-0705-8

Kreibich H, van den Bergh JCJM, Bouwer LM, et al. (2014) Costing natural hazards. Nat Clim Chang 4:303306. doi: $10.1038 /$ nclimate 2182

Lehner B, Döll P, Alcamo J, et al. (2006) Estimating the impact of Global change on flood and drought risks in Europe: A Continental, Integrated analysis. Clim Chang 75:273-299. doi:10.1007/s10584-006-6338-4 
Lung T, Lavalle C, Hiederer R, et al. (2013) A multi-hazard regional level impact assessment for Europe combining indicators of climatic and non-climatic change. Glob Environ Change 23:522-536. doi:10.1016/j. gloenvcha.2012.11.009

Migliavacca M, Dosio A, Camia A, et al. (2013a) Modeling biomass burning and related carbon emissions during the 21st century in Europe. J Geophys Res Biogeosciences 118:2013JG002444. doi:10.1002/ 2013JG002444

Migliavacca M, Dosio A, Kloster S, et al. (2013b) Modeling burned area in Europe with the Community land model. J Geophys Res Biogeosciences 118:265-279. doi:10.1002/jgrg.20026

NatCatSERVICE (2015) Annual statistics 2014, Loss events worldwide 2014, Percentage distribution. Munich Re, Munich, Germany

Nicholls RJ, Klein RJT (2005) Climate change and coastal management on Europe's coast. In: Vermaat J, Salomons W, Bouwer L, Turner K (eds) Managing European Coasts. Springer, Berlin Heidelberg, pp. 199226

Nikulin G, Kjellström E, Hansson U, et al. (2011) Evaluation and future projections of temperature, precipitation and wind extremes over Europe in an ensemble of regional climate simulations. Tellus A 63:41-55. doi:10. 1111/j.1600-0870.2010.00466.x

Outten SD, Esau I (2013) Extreme winds over Europe in the ENSEMBLES regional climate models. Atmos Chem Phys 13:5163-5172. doi:10.5194/acp-13-5163-2013

Pardaens AK, Lowe JA, Brown S, et al. (2011) Sea-level rise and impacts projections under a future scenario with large greenhouse gas emission reductions. Geophys Res Lett 38:L12604. doi:10.1029/2011GL047678

Perkins SE, Alexander LV (2012) On the Measurement of heat waves. J Clim 26:4500-4517. doi:10.1175/JCLID-12-00383.1

Rojas R, Feyen L, Bianchi A, Dosio A (2012) Assessment of future flood hazard in Europe using a large ensemble of bias-corrected regional climate simulations. J Geophys Res Atmospheres 117:D17109. doi:10. 1029/2012JD017461

Rojas R, Feyen L, Watkiss P (2013) Climate change and river floods in the European Union: Socio-economic consequences and the costs and benefits of adaptation. Glob Environ Change 23:1737-1751. doi:10.1016/j. gloenvcha.2013.08.006

Rummukainen M (2012) Changes in climate and weather extremes in the 21st century. Wiley Interdiscip Rev Clim Chang 3:115-129. doi:10.1002/wcc.160

Russo S, Dosio A, Sterl A, et al. (2013) Projection of occurrence of extreme dry-wet years and seasons in Europe with stationary and nonstationary Standardized precipitation indices. J Geophys Res Atmospheres 118: 7628-7639. doi:10.1002/jgrd.50571

Russo S, Dosio A, Graversen RG, et al. (2014) Magnitude of extreme heat waves in present climate and their projection in a warming world. J Geophys Res Atmospheres 119:12,500-12,512. doi:10.1002/ 2014JD022098

Russo S, Sillmann J, Fischer EM (2015) Top ten European heatwaves since 1950 and their occurrence in the coming decades. Environ Res Lett 10:124003. doi:10.1088/1748-9326/10/12/124003

Sillmann J, Kharin VV, Zhang X, et al. (2013) Climate extremes indices in the CMIP5 multimodel ensemble: Part 1. Model evaluation in the present climate J Geophys Res Atmospheres 118:1716-1733. doi:10.1002/jgrd. 50203

Solomon S (2007) Climate change 2007 - the physical Science Basis: Working Group I contribution to the Fourth assessment Report of the IPCC. Cambridge University Press

Trenberth KE, Dai A, van der Schrier G, et al. (2014) Global warming and changes in drought. Nat Clim Chang 4:17-22. doi:10.1038/nclimate2067 